\title{
The treatment of retained stones in the common bile duct with sodium cholate infusion
}

\author{
CHARLES LANSFORD, SUNDER MEHTA, AND FRED KERN ${ }^{1}$, JR \\ From the Division of Gastroenterology, Department of Medicine, University of Colorado Medical Center, \\ Denver, Colorado
}

SUMMARY Six patients with stones retained in the common bile duct after cholecystectomy and common duct exploration were treated by intraductal infusion of a sodium cholate solution. In the five patients whose stones were between the T-tube and the duodenum the treatment was successful within a few days. A stone became transiently impacted in the ampullary region soon after beginning therapy in three patients and produced mild pancreatitis in two. The only failure was in a patient whose stone was between the T-tube and the liver.

Gallstones are retained in the biliary tree after cholecystectomy with common bile duct exploration in approximately $10 \%$ of patients (Bartlett and Dreyfuss, 1960). Since a second operation upon the bile duct is hazardous, several non-surgical approaches to therapy, including dissolution of the stones by instillation of substances through the T-tube (Pribram, 1947; Torresyap, 1958) and removal of the stones by instrumentation through the T-tube, have been proposed (Bean and Mahorner, 1972; Burhenne, 1973).

The purpose of this report is to describe our experiences in six patients with retained common bile duct stones treated by sodium cholate infusions through the T-tube, as described by Way, Admirand, and Dunphy (1972).

\section{Patients and Methods}

The patients were studied at least four weeks after operation. Their ages and sex are shown in the table. They were fully informed and agreed to participate in the experimental procedure. They were asymptomatic and tests of liver function were normal at the time of study.

\footnotetext{
${ }^{1}$ Requests for reprints should be addressed to: Fred Kern, Jr., MD, Division of Gastroenterology, University of Colorado Medical Center, 4200 E Ninth Avenue, Denver, Co, 80220, USA.

Received for publication 2 October 1973.
}

The solution used contained $100 \mathrm{mM}$ sodium cholate in saline, buffered to $\mathrm{pH} \mathbf{7 \cdot 5}$, and sterilized by millipore filtration. It was allowed to drip into the duct at the rate of $30 \mathrm{ml}$ per hour for a maximum of 10 days.

A central venous pressure manometer, connected to the tubing between the solution and the patient, was kept open to provide an overflow valve. The tube extended $30 \mathrm{~cm}$ above the bile duct, a height judged to be equivalent to maximal pressure normally obtained in the common bile duct (Hallenbeck, 1967). When the stone was lying free between the T-tube and the duodenum, the infusion was directed into the T-tube. When the stone was impacted in the distal common bile duct, a small catheter was passed under fluoroscopic control through the T-tube to a position adjacent to the stone and the solution introduced through the catheter. If the common bile duct was occluded distally, bile and infusate could drain through the T-tube around the small catheter, thus allowing continuous infusion and continuous drainage. When the stone was between the liver and the T-tube, the catheter was passed to a position 'upstream' from the stone so that the infusion flowed back over the stone.

Cholangiograms were taken before beginning treatment and at three-day intervals, or more frequently if indicated. Cholestyramine was administered orally at the first sign of diarrhoea. The dose was regulated by the patient's symptoms, and did not exceed 2 g every two hours. 


\begin{tabular}{|c|c|c|c|c|c|c|}
\hline $\begin{array}{l}\text { Patient } \\
\text { Age and } \\
\text { Sex }\end{array}$ & $\begin{array}{l}\text { Duration } \\
\text { of Perfu- } \\
\text { sion } \\
\text { (Days) }\end{array}$ & $\begin{array}{l}\text { Number } \\
\text { of Stones }\end{array}$ & Location of Stones & Results & Side Effects & Comments \\
\hline $\begin{array}{l}\text { VB } \\
37, F\end{array}$ & 4 & 1 & $\begin{array}{l}\text { Impacted in } \\
\text { distal bile duct }\end{array}$ & Successful & $\begin{array}{l}\text { Mild pancreatitis, } \\
\text { haematobilia, } \\
\text { diarrhoea }\end{array}$ & See text \\
\hline \multirow[t]{2}{*}{$\begin{array}{l}\text { KA } \\
56, M\end{array}$} & 10 & 1 & $\begin{array}{l}\text { Above T-tube in } \\
\text { common hepatic duct }\end{array}$ & Failure & Minimal diarrhoea & \\
\hline & 3 & 1 & $\begin{array}{l}\text { Above T-tube in } \\
\text { common hepatic duct }\end{array}$ & Failure & Severe diarrhoea & \multirow{4}{*}{$\begin{array}{l}\text { Combination } \\
\text { cholate-deoxycholate } \\
\text { infusion } \\
\text { Complete obstruction } \\
\text { few hours after } \\
\text { infusion began }\end{array}$} \\
\hline $\begin{array}{l}\mathrm{CW} \\
19, \mathrm{~F}\end{array}$ & 3 & 2 & $\begin{array}{l}\text { Distal common } \\
\text { bile duct, } \\
\text { partially obstructed }\end{array}$ & Successful & $\begin{array}{l}\text { Diarrhoea, nausea, } \\
\text { pancreatitis }\end{array}$ & \\
\hline $\begin{array}{l}\text { AR } \\
60, M\end{array}$ & 4 & 1 & $\begin{array}{l}\text { Distal common } \\
\text { bile duct, } \\
\text { partially obsrtucted }\end{array}$ & Successful & Diarrhoea & \\
\hline $\begin{array}{l}\mathrm{PC} \\
58, \mathrm{~F}\end{array}$ & 5 & 3 & $\begin{array}{l}\text { Free in distal } \\
\text { common bile duct }\end{array}$ & Successful & Mild diarrhoea & \\
\hline $\begin{array}{l}\text { MF } \\
28, F\end{array}$ & 3 & 2 & $\begin{array}{l}\text { Free in distal } \\
\text { common bile duct }\end{array}$ & Successful & Diarrhoea & $\begin{array}{l}\text { Stone became impacted } \\
\text { within first six hours } \\
\text { of infusion }\end{array}$ \\
\hline
\end{tabular}

Table Results of treatment with sodium cholate infusion

\section{Results}

In all five patients in whom the stone or stones were distal to the T-tube, the stones passed (table).
Cholangiograms before and after treatment in one patient $(\mathrm{CW})$ are shown in figure 1. In four patients, the stones passed after three to five days of infusion, but in the fifth (VB) the stone passed two weeks

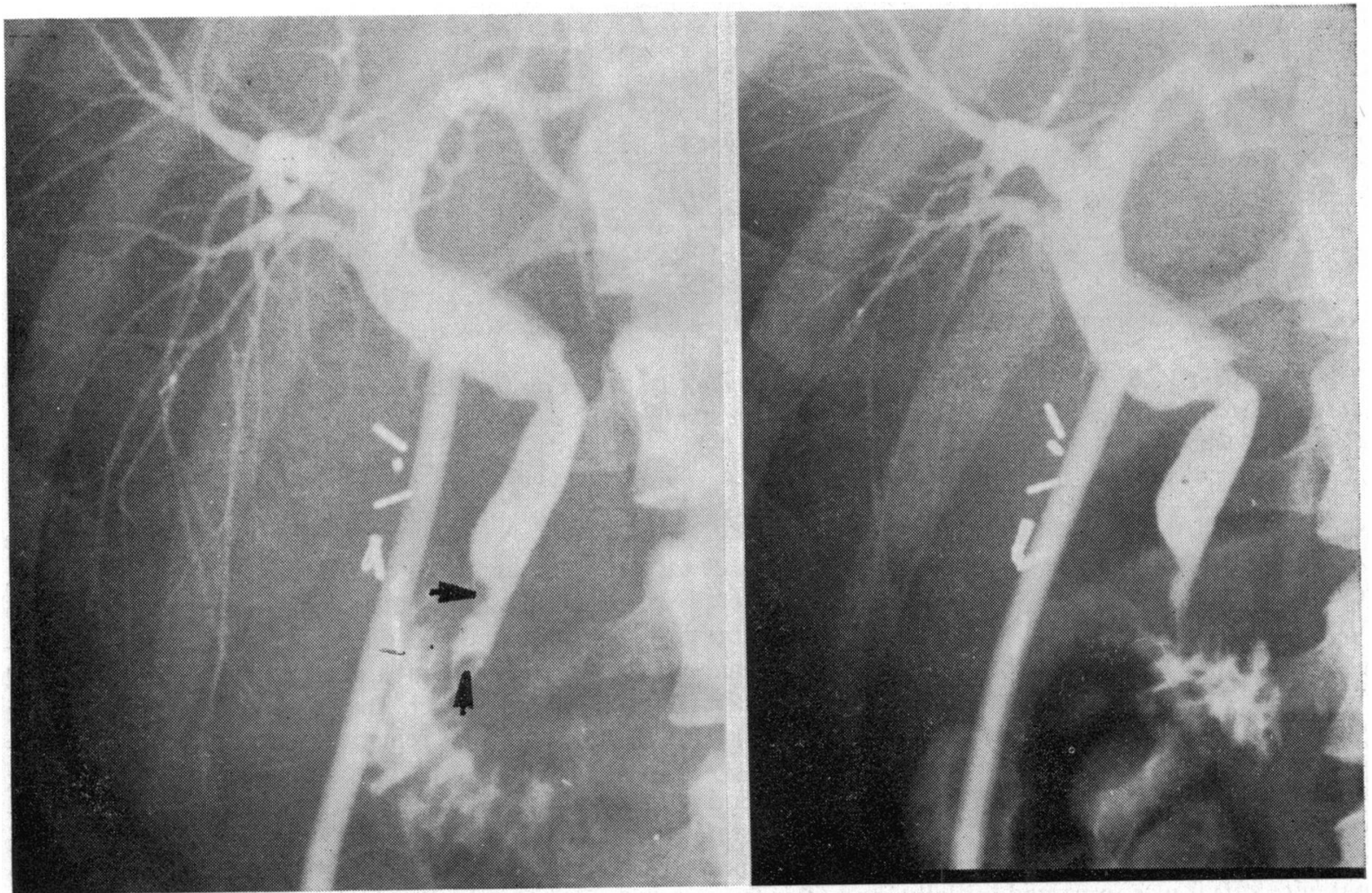

Fig 1 Patient C.W. The left panel shows a cholangiogram before treatment. Arrows point to two definite stones. The right panel shows a cholangiogram after the stones had passed. 
(a)

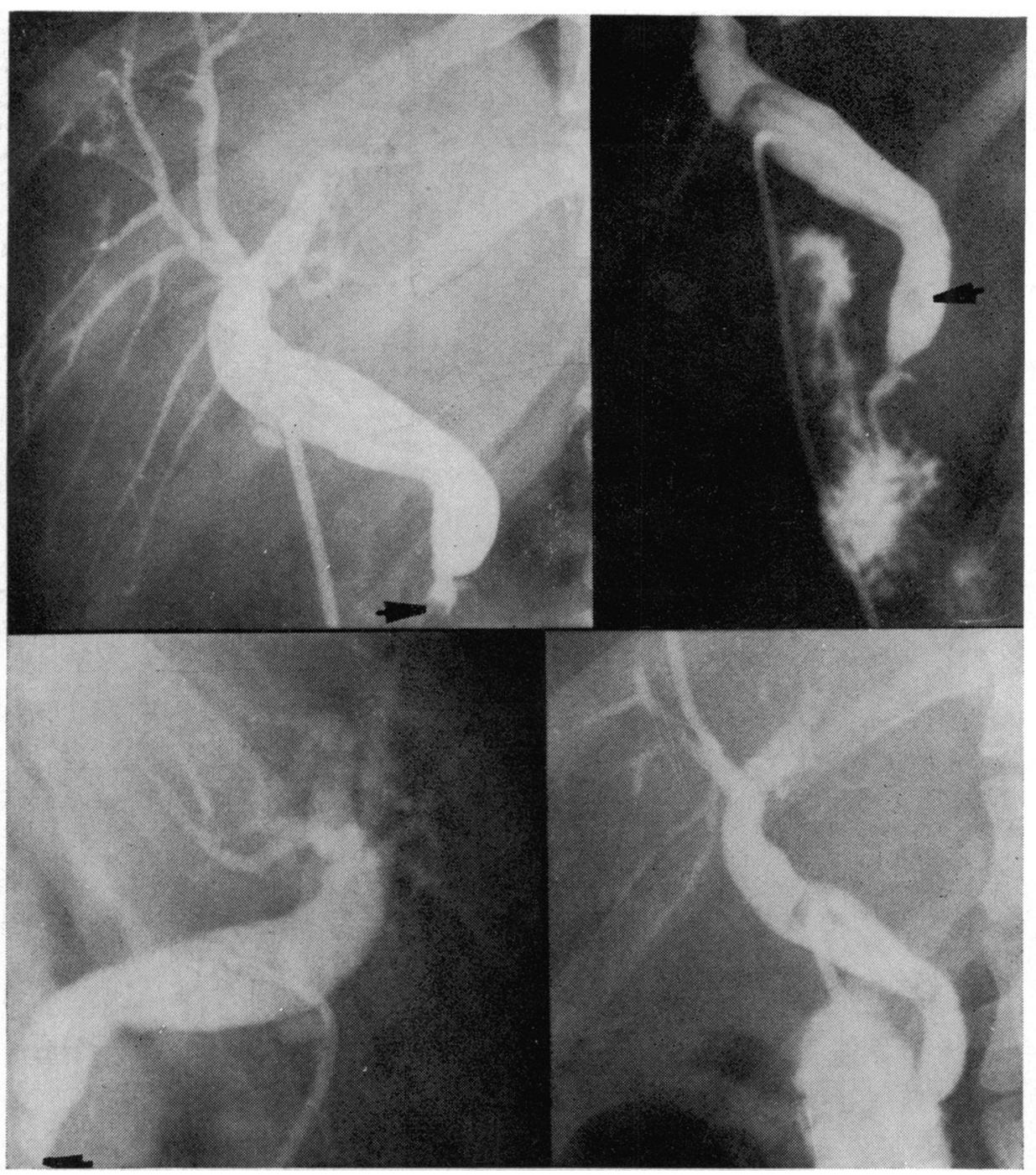

Fig 2 Patient $V . B$. The stone is impacted at the ampulla $(A)$, free in the duct $(\mathrm{B})$, not visible, but completely occluding the duct (C), and no longer present (D). The T-tube was withdrawn and the patient did well. Arrows indicate the stone.

after a four-day infusion had been completed.

There were minor, but potentially important complications in three of the five patients who were treated successfully. In all three, a stone became transiently impacted in the distal bile duct associated with a rise in intraductal pressure and pain in the epigastrium and back. Mild pancreatitis developed in two; both had slightly elevated serum and urinary amylase levels, and one had an elevated white blood count. In two patients, the stone was free in the distal duct at the beginning of the infusion. In the other patient (VB) it was impacted initially, and after four days of cholate infusion, there developed mild midepigastric pain and a small amount of blood appeared in the bile. A cholangiogram showed the stone to bes free in the duct (figure 2). The infusion was stopped she became asymptomatic, and was discharged. Two weeks later, upon readmission to hospital, a cholan giogram showed that the stone was again impacted? in the distal bile duct. The next day before the cholate infusion could be reinstituted, the signs and symp $\frac{\text { Oे }}{8}$ toms of pancreatitis developed and after two days? the stone passed and the patient became asympto- 2 matic. In all three patients the obstruction lasted less than 48 hours and was followed by passage of the stone into the duodenum.

In the one failure (KA), the stone was proximab. to the tube. That patient was treated for 10 days 
with a sodium cholate infusion and later for three days with a $100 \mathrm{mM}$ mixture of $70 \%$ sodium cholate and $30 \%$ sodium deoxycholate, The second infusion had to be terminated because of uncontrollable diarrhoea.

\section{Discussion}

In four of the five patients with retained stones in the common bile duct distal to the T-tube, the stones passed out of the duct within five days of beginning the sodium cholate infusion. In the fifth patient the stone passed two weeks after the infusion. Was this the natural history of the disease, the mechanical effect of bile duct perfusion, or a specific effect of the bile salt solution.

Common bile duct stones do pass into the duodenum spontaneously, but since they had not passed in these patients during the preceding four to six weeks of observation, spontaneous passage seems unlikely.

A non-specific effect of bile duct perfusion cannot be excluded in these patients because we did not use a control saline solution, but other studies suggest that bile duct perfusion alone would not give these results. Way et al, (1972) used saline in four patients for six days without passage of the stones but in all four the stones passed during the sodium cholate infusions. Furthermore, since maximum intraductal pressure was maintained at a level no greater than normal intraductal pressure, it seemed very doubtful that the stones were forced or flushed out of the duct.

Small (1970) and Earnest and Admirand (1971) showed that incubation of cholesterol stones in bile salt solutions in vitro dissolves some cholesterol out of the stones and decreases their size. In our patients the stones did not dissolve nor was it possible to detect radiographically a decrease in size. It is highly probable, however, that a decrease in size sufficient to allow passage into the duodenum did occur. This view is supported by the impaction of stones in the ampullary region in two patients only a few hours after beginning the infusions. In those patients the stones had remained free in the bile duct without entering the narrower intraduodenal portion for four to six weeks before the bile salt infusions.

The only complications of therapy were diarrhoea in all patients and the transient impaction of the stone in the ampulla of a Vater, causing mild pancreatitis in two patients. The diarrhoea was easily controlled with cholestyramine in all patients except the one who was given a mixture of sodium cholate and sodium deoxycholate. The deoxycholate was employed because of its greater cholesterol solubilizing capacity (Earnest and Admirand, 1971). Pancreatitis is a potentially serious complication, but in these patients it was mild and transient.

On the basis of our experience we recommend continued use of sodium cholate infusion into the common bile duct to treat retained stones, especially when the stones are between the T-tube and the duodenum.

This investigation was supported by United States Public Health Service research grant AM 12626 and the General Clinical Research Centers Program of the National Institutes of Health, FR 00051. Dr Lansford was supported by a Veterans Administration training grant in gastroenterology, TR 110.

\section{References}

Bartlett, M. K., and Dreyfuss, J. R. (1960). Residual common duct stones. Surgery, 47, 202-205.

Bean, W. J., and Mahorner, H. R. (1972). Removal of residual biliary stones through the T-tube tract. Sth. med. J. (Bgham, Ala.), 65, 377-378.

Burhenne, H. J. (1973). Nonoperative retained biliary tract stone extraction. Amer. J. Roentgenol., 117, 388-399.

Earnest, D. E., and Admirand, W. H. (1971). The effects of individual bile salts in cholesterol solubilization and gallstone dissolution. Gastroenterology, 60, 772.

Hallenbeck, G. A. (1967). Biliary and pancreatic intraductal pressures. In Handbook of Physiologv, Sect 6, Alimentary Canal, edited by C. F. Code, Vol. II, pp. 1007-1025. American Physiological Society, Washington, D.C.

Pribram, B. O. C. (1947). The method for dissolution of common duct stones remaining after operation. Surgery, 22, 806-818.

Small, D. M. (1970). The formation of gallstones. Advanc. intern. Med., 16, 243-264.

Torresyap, F. C. (1958). Chloroform instillation of common bile duct. Arch. Surg., 77, 903-907

Way, L. W., Admirand. W. H., and Dunphy, J. E. (1972). Management of choledocholithiasis. Ann. Surg., 176, 347-359. 